\title{
A HISTÓRIA AMBIENTAL COMO CAMPO HISTORIOGRÁFICO E SUA OFERTA COMO DISCIPLINA NOS CURSOS DE GRADUAÇÃO EM HISTÓRIA EM GOIÁS NO ANO DE 2018
}

\author{
Jéssica Dafico Moreira da Costa Gomes \\ Universidade Estadual de Goiás \\ Anápolis - Goiás - Brasil \\ E-mail: jessica_gomes18@hotmail.com \\ ORCID: https://orcid.org/0000-0002-8032-6590

\section{Adriana Aparecida Silva} \\ Universidade Estadual de Goiás \\ Anápolis - Goiás - Brasil \\ E-mail: ueg.adriana@gmail.com \\ ORCID: https://orcid.org/0000-0002-8711-1517
}

Recebido em 09/06/2020. Aprovado em 25/11/2020

DOI: dx.doi.org/10.5380/guaju.v6i2.74415

\section{Resumo}

A disciplina de história ambiental, introduzida no meio acadêmico no início da década de 1970, traz consigo uma nova maneira de se estudar a história, rompendo com a ótica dualista e determinista vigente à época, de modo a considerar a interrelação entre ser humano e meio natural como ponto fundamental para a análise historiográfica. Com o intuito de verificar a relevância da disciplina de história ambiental nos cursos de graduação em história, analisou-se as matrizes curriculares dos cursos de graduação presenciais, ofertados em Goiás, comparando-as às grades dos 10 melhores cursos de graduação em história do país utilizando o ranking elaborado pela Folha de São Paulo, em 2018. Verificou-se que, embora transcorrido 49 anos, desde a primeira vez que a disciplina de história ambiental foi ofertada no mundo, sua inserção nos cursos de graduação em história no Brasil ainda é escassa, estando presente em apenas $20 \%$ dos cursos pesquisados, apontando para o desprestígio desta matéria em termos de concepção da relevância de se estudar a história tendo como base a inter-relação entre o ser humano e a natureza no campo historiográfico.

Palavras-chave: História Ambiental; Meio ambiente; Historiografia; Disciplinas. 


\title{
Enviromental History as a Historiographic Field and Its Offer as a Discipline at History Graduation Courses in Goiás in the Year of 2018
}

\begin{abstract}
The environmental history discipline, introduced to the academic environment at the beginning of the 1970s, brings a new way of studying history, breaking with the dualist and deterministic viewpoint prevailing at the time, to consider the interrelationship between being human and the natural environment as a fundamental point for historiographical analysis. To verify the environmental history relevance in undergraduate history courses, the undergraduate history courses curricular matrices offered in Goiás were analyzed, comparing them to the 10 best undergraduate history courses curriculum in the country using the ranking prepared by Folha de São Paulo in 2018. It was found that, although 49 years have passed since the first time that the environmental history discipline was offered in the world, its insertion in undergraduate history courses in Brazil are still scarce, being present in only $20 \%$ of the courses surveyed, pointing to the lack of prestige of this matter in terms of conceiving the relevance of studying history, based on the interrelationship between human beings and nature in the historiographic field.
\end{abstract}

Keywords: Environmental history; Environment; Historiography; Subjects. 


\section{Introdução}

O modelo antigo de se estudar e ministrar a disciplina de história, chamada de "velha história" por Donald Worster, emerge de um cenário em que esta área do saber se limitava à análise política, sujeita aos interesses do Estado. Este pensamento perdurou especialmente durante o século XIX e início do século XX, arraigado por ideias patriotas e de cunho político, as quais conduziam o modo de se fazer história naquela época (WORSTER, 1991).

Porém, após esse período, iniciou-se uma mudança nos paradigmas e visões no campo da historiografia. Parte desta mudança se deu em função da constatação do caráter limitado do estudo da história, adstrito aos aspectos políticos e econômicos, considerando as constantes transformações às quais estão sujeitas a sociedade ao longo do tempo. Outro fator que contribuiu para a alteração da antiga visão se deu a partir da percepção de alguns historiadores em se dedicar e atentar aos aspectos sociais e ambientais, considerando especialmente a interação humana com o meio ambiente e as consequências desta ao se analisar a história (SOUZA, 2011).

Paralelo a isto, há que se destacar o despertar mundial, especialmente no período pós-guerra, para questões ambientais e à sustentabilidade, o que se materializou em 1972 através da primeira conferência mundial convocada pela Organização das Nações Unidas (ONU) para tratar sobre o Ambiente Humano, a chamada Conferência de Estocolmo. A declaração final produzida nesta conferência resultou na edição de 26 princípios norteadores, estabelecendo diretrizes pautadas na proteção e cooperação internacional nas políticas ambientais (NAÇÕES UNIDAS NO BRASIL, 2018; MINISTÉRIO DO MEIO AMBIENTE, 2018). Dentre estes princípios, destaca-se o 19 e 20, os quais tratam dos esforços em termos de ensino e pesquisas que ressaltem a necessidade de se incluir os elementos naturais em conjunto com a dimensão humana.

Princípio 19

É indispensável um esforço para a educação em questões ambientais, dirigida tanto às gerações jovens como aos adultos e que preste a devida atenção ao setor da população menos privilegiado, para fundamentar as bases de uma opinião pública bem informada, e de uma conduta dos indivíduos, das empresas e das coletividades inspirada no sentido de sua responsabilidade sobre a proteção e melhoramento do meio ambiente em toda sua dimensão humana. É igualmente essencial que os meios de comunicação de massas evitem contribuir para a deterioração do meio ambiente humano e, ao contrário, difundam informação de caráter educativo sobre a necessidade de protegê-lo e melhorá-lo, a fim de que o homem possa desenvolver-se em todos os aspectos. 


\begin{abstract}
Princípio 20
Devem-se fomentar em todos os países, especialmente nos países em desenvolvimento, a pesquisa e o desenvolvimento científicos referentes aos problemas ambientais, tanto nacionais como multinacionais. Neste caso, o livre intercâmbio de informação científica atualizada e de experiência sobre a transferência deve ser objeto de apoio e de assistência, a fim de facilitar a solução dos problemas ambientais. As tecnologias ambientais devem ser postas à disposição dos países em desenvolvimento de forma a favorecer sua ampla difusão, sem que constituam uma carga econômica para esses países (ONU, 1972).
\end{abstract}

Neste cenário, surge nos Estados Unidos, na década de 1970, a disciplina história ambiental, resultado da sensibilidade e atenção dos historiadores às inquietações da época, bem como à necessidade de se ampliar o campo de visão da história de modo a propiciar uma nova dimensão de tempo e espaço por meio das relações entre o ser humano e o meio ambiente nas análises historiográficas (DUTRA E SILVA et al., 2017).

Foi no ano de 1972, na Universidade da Califórnia nos Estados Unidos, que surgiu o primeiro notório curso em nível acadêmico intitulado "História Ambiental", o qual foi idealizado e ministrado por Roderick Nash. Nash (1972, apud PÁDUA, 2010, p. 81), ao explicar o que o levou à criação deste curso, afirmou categoricamente estar "[...] respondendo aos clamores por responsabilidade ambiental que atingiram um crescendo nos primeiros meses daquele ano". Esta fala evidencia a influência direta das demandas mundiais e dos discursos políticos do período na concepção do curso e, consequentemente, na consolidação da história ambiental norte americana.

É inegável a presença política neste processo de formação da história ambiental, uma vez que, como visto, especialmente no início da década 1970, esta pauta ganhou repercussão mundial e levou vários países a se comprometerem com a preservação ambiental. Porém, a história ambiental não se limitou apenas aos anseios políticos e clamores mundiais temporais, ela se desenvolveu e se estruturou como campo historiográfico com o foco em estabelecer uma análise quanto à relação interativa dos seres humanos com o meio natural e a forma como um influencia o outro ao longo do tempo (WORSTER, 1991).

Há que se destacar que a história ambiental enquanto disciplina curricular se consolida na década de 1970, todavia, a relevância e percepção do estudo da natureza na historiografia remete à década de 1940, destacando-se o trabalho desenvolvido por Fernand Braudel em 1944 ao analisar o ser humano enquanto essência biológica vulnerável às interferências da natureza, tal como frio e calor (BRAUDEL, 1944 apud PÁDUA, 2010). Analisar tais referências é fundamental para se entender as bases evolutivas do que hoje se 
tem consolidado enquanto disciplina acadêmica e, para além disso, compreender o avanço do estudo da inter-relação da natureza para com o ser humano e seus reflexos no campo historiográfico.

Nesse sentido, Pádua (2010) desenvolve uma análise histórica acerca da história ambiental, na qual destaca as transformações epistemológicas ocorridas na década de 1970 como um dos fatores que estimulou os historiadores ambientais a analisarem de uma nova forma as relações interativas do ser humano com o ambiente natural ao qual está inserido, destacando três principais mudanças ocorridas:

1) a ideia de que a ação humana pode produzir um impacto relevante sobre o mundo natural, inclusive ao ponto de provocar sua degradação; 2) a revolução nos marcos cronológicos de compreensão do mundo; e 3) a visão de natureza como uma história, como um processo de construção e reconstrução ao longo do tempo (PÁDUA, 2010, p. 63).

A história ambiental surge, então, junto com a ideia de ampliar a visão anteriormente utilizada na história de modo a não mais se firmar em uma visão reducionista, alheia à inserção do ser humano e das experiências por ele vivenciadas e aos reflexos no ambiente natural, assim descrito por Donald Worster (1991, p. 199):

\begin{abstract}
A história ambiental é, em resumo, parte de um esforço revisionista para tornar a disciplina da história muito mais inclusiva nas suas narrativas do que ela tem tradicionalmente sido. Acima de tudo, a história ambiental rejeita a premissa convencional de que a experiência humana se desenvolveu sem restrições naturais, de que os humanos são uma espécie distinta e "supernatural", de que as conseqüências (sic) ecológicas dos seus feitos passados podem ser ignoradas. A velha história não poderia negar que vivemos neste planeta há muito tempo, mas, por desconsiderar quase sempre esse fato, portou-se como se não tivéssemos sido e não fôssemos realmente parte do planeta. Os historiadores ambientais, por outro lado, perceberam que não podemos mais nos dar ao luxo de sermos tão inocentes.
\end{abstract}

Percebe-se, assim, que a história ambiental proporcionou a percepção de uma nova forma de se estudar a história, abrindo os horizontes dos historiadores para necessidade de considerar seus objetos de estudo de uma forma muito mais ampla e integrada do que vinha sendo feito até então, já que, sob antiga ótica, ao isolar o ser humano do meio natural, por consequência, desconsidera-se a relação de interação que existe entre estes, o que é incontestável e altera grandemente o resultado da análise. 
Diante da relevância do estudo da história ambiental, tratando-se de uma disciplina tipicamente relacionada ao curso de história, objetivou-se por meio do presente trabalho identificar a oferta da disciplina no Brasil e, para tanto, estabeleceu-se como critério a análise das matrizes curriculares dos cursos de graduação em história disponíveis no estado de Goiás e, ainda, dos 10 melhores cursos de história do país, considerando como critério classificatório o ranking estabelecido pela pesquisa desenvolvida pela Folha de São Paulo no ano de 2018 (RUF - Ranking Universitário Folha) o qual desenvolve um ranqueamento anual dos cursos superiores ativos no país (FOLHA DE SÃO PAULO, 2019).

\section{A história ambiental como campo historiográfico}

A história ambiental tem por objetivo quebrar a visão dualista de análise da história, e estimular uma nova perspectiva por meio da inclusão do estudo de aspectos sociais, culturais, ambientais, políticos e econômicos de modo a favorecer um resultado mais amplo no campo das análises históricas. Essa visão ampliada agrega ainda mais como fonte de estudo e pesquisa diante da contribuição de conceitos e experiências advinda de outras áreas dos saberes, não se limitando à análise puramente historiográfica de maneira isolada das outras ciências (PÁDUA, 2010).

Além disto, notória é a influência do meio natural nos processos históricos, o que afasta a ideia de que apenas o ser humano interfere na natureza, desconsiderando a mútua interferência. As questões climáticas que influenciaram no volume de produção agrícola, refletindo diretamente na economia, a forma de ocupação de territórios definidas pelos fluxos dos rios e, sobretudo, os grandes terremotos e furações que destruíram civilizações são exemplos de como o ambiente impactou e permanece influenciando a história da sociedade desde sua constituição até os dias atuais (WORSTER, 1991).

Dentre as muitas concepções aplicadas à história ambiental, Donald Worster desenvolveu uma importante análise ao estabelecer três níveis essenciais para se estudar a matéria, os quais se pautam em: natureza; fator socioeconômico e fator mental ou intelectual. O primeiro se refere a natureza em si "[...] tal como se organizou e funcionou no passado; incluímos aí tanto os aspectos orgânicos quanto inorgânicos da natureza, inclusive o organismo humano..." (WORSTER, 1991, p. 202). O segundo trata da interação social e econômica sobre o ambiente, explorando a forma de trabalho e produção de bens. Por último, o terceiro aspecto se relaciona a maneira com a qual o ser humano vivencia os dois últimos elementos, abarcando sentimentos e emoções (WORSTER, 1991). 
Entender os três níveis estabelecidos por Worster (1991) demonstra a relevância de se analisar conjuntamente estes elementos e propicia a libertação de uma visão isolada da história, ao passo que se percebe que a relação ser humano - meio natural é, em verdade, uma relação de causa e efeito, na qual se predomina a interdependência e não a subordinação de um agente sobre o outro (SOUZA, 2013). A compreensão de que o mundo permanece em constante transformação, e que o ser humano é protagonista nas alterações na natureza, orquestrou uma verdadeira revolução na forma de se enxergar a história, rompendo com a antiga ideia determinista de que a natureza e os fenômenos naturais regiam o mundo, sendo então considerado que o conceito de determinismo ecológico representa uma ameaça à perfeita análise da história ambiental (PÁDUA, 2010).

Desta forma, é possível inferir que a história ambiental trouxe consigo não somente um novo campo historiográfico a ser explorado, mas sim uma nova visão da história, rompendo barreiras e antigos paradigmas e conceitos perpetuados ao longo de gerações, os quais impossibilitavam a análise da relação existente entre os seres humanos e o ambiente. Conforme demonstrado, as contribuições da história ambiental como campo historiográfico, inovaram e desafiaram a antiga forma de se estudar a história. Além da inserção do estudo da inter-relação ser humano - ambiente, incorporou-se à análise aspectos até então menosprezados advindos das ciências políticas, sociais e econômicas, trazendo à baila a importância da interdisciplinaridade e do estudo multifocal de um objeto em sua perspectiva histórica, trazendo à tona a ideia de um saber unificado, defendida por Pombo (2005).

É fundamental que este campo historiográfico como disciplina seja estimulado e difundido nos ambientes acadêmicos universitários envolvendo o ensino e a pesquisa interdisciplinar, possibilitando a expansão do conhecimento e das discussões históricoambientais tão atuais e necessárias. Neste sentido, as Universidades devem cumprir com seu papel fundamental, que não é apenas a formação técnico-profissional dos acadêmicos e inserção destes no mercado de trabalho, mas para muito além disso, formar agentes atuantes e pensantes mediante a formação científica.

Renata Sartori destaca o importante papel das Universidades no que diz respeito à formação profissional, em especial, no campo das pesquisas.

O papel da universidade é muito importante nesse aspecto por ser considerada estimuladora de conhecimento com mais rigor metodológico. $A$ realização de pesquisas científicas de alto nível, a formação de pesquisadores 
competentes e a elaboração de teses acadêmicas constituem função altamente relevante e mesmo imprescindível para o desenvolvimento do país (SARTORI, 2005, p. 16).

Enquanto fomentadoras de conhecimento e pesquisa, as universidades devem se preocupar em trabalhar com ofertas de disciplinas clássicas como também contemporâneas, de modo a estimular o pensamento crítico e possibilitar um desenvolvimento acadêmico em consonância com a urgente necessidade da análise integrada das diversas áreas do conhecimento. A exemplo disto, a disciplina de história ambiental ainda não é considerada como um campo historiográfico clássico nos cursos de graduação em história no Brasil, muito embora exista o apontamento da contribuição dos conhecimentos advindos do estudo histórico-ambiental para a formação do historiador por meio da reflexão da inter-relação que envolve o ser humano e o meio natural, como base para o estudo dos mais variados fenômenos e eventos históricos, se desvencilhando, assim, da antiga práxis limitada de se estudar a história.

\section{A oferta da disciplina de história ambiental}

No que tange aos cursos de graduação em história ofertados no estado de Goiás apurou-se, primeiramente, quais universidades e faculdades do estado ofereciam o curso na modalidade presencial. Em sequência, por meio de pesquisa nos sítios eletrônicos destas instituições educacionais, buscou-se as matrizes curriculares de cada um destes cursos, averiguando quais deles ofereciam a disciplina de história ambiental, fossem elas obrigatórias ou optativas.

Cumpre destacar que se optou por analisar os cursos disponíveis apenas na modalidade presencial, não abarcando os cursos semipresenciais e à distância, isto por critério de delimitação do objeto de estudo, uma vez que caso considerássemos os cursos ofertados na modalidade à distância, indiretamente estaríamos analisando cursos disponibilizados em outros estados do país. Percebeu-se que a maioria das grades dos cursos ofertados na modalidade à distância são fixas, independentemente do estado onde o curso é oferecido, não havendo, portanto, um programa pontual de estruturação da grade curricular específica para cada curso disponibilizado pelas instituições que adotam tal modalidade de ensino. Deste modo, tal modalidade não contribui para a análise aqui proposta diante da impossibilidade de se fazer um recorte espacial preciso, o que somente é possível mediante à análise dos cursos presenciais. 
Além disto, o Ranking Universitário dos 10 melhores cursos de história do país utilizado nesta pesquisa, contempla estritamente cursos presenciais, independentemente se ofertados por instituições públicas ou privadas, portanto, fundamental se faz a utilização do mesmo parâmetro para se desenvolver uma análise comparativa do cenário regional ao nacional. Seguindo esse mesmo critério, também foram analisados no âmbito do estado de Goiás apenas os cursos de história ofertados na modalidade presencial.

Das 81 instituições de ensino analisadas, identificou-se que, ao todo, são ofertados no estado de Goiás 15 cursos de graduação em história, ministrados na modalidade presencial dos quais apenas a Universidade Federal de Goiás - UFG oferece a graduação na modalidade bacharelado e também licenciatura, os demais todos disponíveis apenas na modalidade licenciatura (BUSCA FACULDADE, online). Dentre estes, apenas 2 (dois) oferecem em sua grade a disciplina de história ambiental, sendo os cursos oferecidos pelo Instituto Federal de Goiás - IFG e pela Universidade Estadual de Goiás - UEG, exclusivamente no Campus Goianésia, inexistindo nas matrizes curriculares dos demais cursos nenhuma disciplina correlata (tabela 1). 
Tabela 1: Relação Faculdade/Universidade sediadas no Estado de Goiás que oferecem o curso de graduação em história x Oferta da disciplina de história ambiental, 2018.

\begin{tabular}{|l|l|}
\hline Faculdade/Universidade & Oferece a disciplina de história ambiental? \\
\hline $\begin{array}{l}\text { UEG CAMPUS DE CIÊNCIAS SÓCIO-ECONÔMICAS E } \\
\text { HUMANIDADES }\end{array}$ & Não \\
\hline UEG CAMPUS FORMOSA & Não \\
\hline UEG CAMPUS GOIANÉSIA & Sim \\
\hline UEG CAMPUS GOIÁS & Não \\
\hline UEG CAMPUS IPORÁ & Não \\
\hline UEG CAMPUS ITAPURANGA & Não \\
\hline UEG CAMPUS MORRINHOS & Não \\
\hline UEG CAMPUS PIRES DO RIO & Não \\
\hline UEG CAMPUS PORANGATU & Não \\
\hline UEG CAMPUS QUIRINÓPOLIS & Não \\
\hline UEG CAMPUS URUAÇU & Não \\
\hline UFG & Não \\
\hline PUC GOIÂNIA & Não \\
\hline FACULDADE ALFREDO NASSER & Não \\
\hline IFG & Sim \\
\hline
\end{tabular}

Fonte: Elaborado pela autora segundo dados extraídos dos sites das respectivas instituições de ensino.

Como característica comum entre esses dois cursos, percebe-se que ambos são ofertados por instituições públicas de ensino, além disso, a disciplina de história ambiental é disponibilizada exclusivamente na modalidade optativa, não sendo essa, portanto, considerada de cunho obrigatório à formação destes futuros historiadores e historiadoras.

Cumpre destacar a diferente nomenclatura dada às disciplinas pautadas no estudo da história ambiental ofertadas no estado de Goiás. Na UEG no Campus Goianésia essa fora denominada "História Ambiental e Sustentabilidade", enquanto no IFG a disciplina é intitulada "Tópicos Especiais em História, Meio Ambiente e Educação Ambiental". Percebe-se que, em ambas, além do estudo da relação história e meio ambiente há destaque também para o enfoque em proteção e preservação ambiental, o que pode ser observado em razão da inclusão dos termos "sustentabilidade" e "educação ambiental" ao título das disciplinas.

Com relação à Universidade Estadual de Goiás, que possui o curso de história em 11 (onze) de seus Campi distribuídos pelo interior do estado, cabe destacar que, desde o ano de 2015, o Projeto Pedagógico do Curso (PPC), foi definido por Campus de modo que cada um 
desses cursos de história possui uma estrutura curricular própria. Algumas disciplinas ditas como padrão se repetem nas grades observadas, porém, dentre todos, apenas o Campus Goianésia se ateve em incluir a disciplina voltada ao estudo da história ambiental como uma disciplina optativa aos acadêmicos.

É importante dizer que as grades curriculares da Universidade Estadual de Goiás são compostas por núcleo específico e núcleo livre, sendo o primeiro correspondente às disciplinas obrigatórias para a conclusão do curso e o segundo um composto de disciplinas optativas as quais os acadêmicos poderão escolher qual dessas cursará. Assim, nesse modelo educacional de estruturação curricular os ditos "núcleos livres" visam fornecer ao aluno uma formação humana que excede os limites das grades curriculares pré-estabelecidas de modo a possibilitar uma expansão do pensamento intelectual e da formação acadêmica (UNIVERSIDADE ESTADUAL DE GOIÁS, online).

É interessante destacar que, segundo informações disponibilizadas no site da Universidade Estadual de Goiás, a própria instituição recomenda que as disciplinas propostas como núcleo livre abarquem, preferencialmente, temas abordados pelo Exame Nacional de Desempenho dos Estudantes (ENADE) que, dentre os muitos assuntos elencados, aponta a temática de "meio ambiente" como possível objeto de estudo (UNIVERSIDADE ESTADUAL DE GOIÁS, online).

Outro aspecto interessante do formato curricular dessa instituição é que as disciplinas ofertadas como núcleo livre, como é o caso da disciplina "História Ambiental e Sustentabilidade", pode ser frequentada por alunos de qualquer curso e/ou de qualquer Campus da instituição, ou seja, embora apenas o Campus Goianésia ofereça a disciplina voltada para a temática de história ambiental, em tese, qualquer aluno regularmente matriculado na Universidade que tenha interesse em cursar essa disciplina poderá assim fazêlo, desde que haja vaga quando do momento da solicitação de matrícula (UNIVERSIDADE ESTADUAL DE GOIÁS, online).

Embora exista essa possibilidade abrangente de acesso à disciplina, devemos considerar a dificuldade dada a grande extensão territorial do estado de Goiás, uma vez que a depender da distância entre o domicílio do aluno e o Campus onde se oferta a disciplina, bem como a agenda curricular do curso de graduação em que o aluno está matriculado, constitui-se um cenário difícil para que esse possa ter acesso à disciplina em específico e a essa modalidade de oferta de disciplinas como um todo. Além disto, deve-se considerar a limitação de vagas oportunizadas para disciplinas de núcleo livre isso porque, como a 
disciplina é aberta a todos os alunos da instituição, existe a possibilidade de grande procura no próprio Campus, o que reduz ainda mais a possibilidade de acesso à disciplina.

Assim, considerando os dados apurados, verifica-se que no Estado de Goiás a oferta da disciplina de história ambiental é insuficiente e extremamente baixa considerando que, dentre os 15 (quinze) cursos de graduação presencial em história no estado, apenas 2 (dois) possuem a disciplina inserida em sua matriz curricular. Porém, em termos de relevância temática, como já dito, em ambos há a oferta da disciplina unicamente na modalidade optativa, o que demonstra o desprestígio da disciplina de história ambiental no âmbito acadêmico goiano. Muito embora no caso da disciplina ofertada pela Universidade Estadual de Goiás - Campus Goianésia exista a possibilidade de que alunos interessados na temática, mas matriculados em outros Campus possam cursá-la enquanto optativa, a oferta de vagas é limitada e o fator do aluno ter que se deslocar de sua cidade para cursar apenas essa disciplina certamente diminui a possibilidade de acesso efetivo.

Como visto, a história ambiental não se limita exclusivamente à estudos ambientais, tal disciplina se dedica à análise da influência mútua do ser humano - meio ambiente e do meio na história humana, incluindo nessa análise elementos sociais, econômicos e políticos. A baixa inserção da disciplina de história ambiental nas grades dos cursos de história ofertados em Goiás, demonstra claramente a insuficiente relevância deste campo historiográfico nos cursos ministrados no estado e a limitação da visão dessas instituições quanto à importante contribuição da disciplina para a formação acadêmica dos futuros historiadores e historiadoras.

De modo a produzir uma análise comparativa dos cursos de história ministrados presencialmente no estado de Goiás ao cenário nacional, elencou-se os 10 (dez) melhores cursos de história do país em 2018, a partir da pesquisa realizada anualmente pela Folha de São Paulo a qual foi elaborada com base em indicadores extraídos do Censo da Educação Superior do Inep-MEC, Enade, SciELO, Web of Science, Inpi, Capes, CNPq, fundações estaduais de fomento à ciência e em duas pesquisas anuais feitas pelo Datafolha (FOLHA DE S. PAULO, 2018)

Percebe por meio da análise dos dados contidos na Tabela 2 que dos 10 (dez) cursos de história considerados como os melhores do país, apenas 3 (três) desses oferecem a disciplina de história ambiental, sendo: Universidade Federal do Rio de Janeiro - UFRJ, Universidade de Brasília - UNB e Universidade do Estado de São Paulo - UNESP, o que representa $30 \%$ dos cursos acima descritos. 
Tabela 2: Relação dos 10 melhores cursos de história classificados por Universidades/Faculdade x Oferta da disciplina de história ambiental, 2018.

\begin{tabular}{|l|l|l|}
\hline CLASSIFICAÇÃo & Faculdade/Universidade & $\begin{array}{l}\text { Oferece a disciplina de história } \\
\text { Ambiental? }\end{array}$ \\
\hline $1^{\circ}$ & UNICAMP & Não \\
\hline $2^{\circ}$ & UFRJ & Sim \\
\hline $3^{\circ}$ & UFMG & Não \\
\hline $4^{\circ}$ & USP & Não \\
\hline $5^{\circ}$ & UFF & Não \\
\hline $6^{\circ}$ & UFRGS & Não \\
\hline $7^{\circ}$ & UNB & Sim \\
\hline $8^{\circ}$ & PUCSP & Não \\
\hline $9^{\circ}$ & UNESP & Sim (Campus Assis) \\
Não (Campus Franca)
\end{tabular}

Fonte: Elaborado pela autora segundo dados extraídos da Folha de S. Paulo, Ranking Universitário Folha -RUF, 2019.

Nesse ranking dos melhores cursos de história do Brasil, apurado pela Folha de São Paulo - RUF, foi estabelecida uma classificação com base no desempenho do curso oferecido pela Universidade, sendo considerada como uma instituição única, não se atendo à uma classificação isolada por campus. A UNESP, por exemplo, citada como o $9^{\circ}$ melhor curso de história, disponibiliza o curso de História em dois campi, um sediado na cidade de Assis e outro em Franca, como não há uma individualização por parte da pesquisa elaborada pela Folha de São Paulo com relação à cada um destes cursos, nesse caso em específico, para fins metodológicos, analisou-se a matriz curricular dos dois conjuntamente.

Analisando a matriz curricular destes dois cursos oferecidos pela UNESP, percebeuse que essas diferem entre si, sendo que apenas no Campus de Assis há a oferta da disciplina de história ambiental. Esse curso merece especial destaque, pois dentre todos os cursos de história apurados nessa pesquisa é o único que oferece a disciplina de história ambiental na modalidade obrigatória. Além disso, esse Campus da UNESP em Assis apresenta, ainda, um centro de pesquisa específico voltado para a temática, trata-se do Laboratório de História e Meio Ambiente (LABHIMA), fundado em 2003, o qual tem como um dos seus objetivos o fortalecimento dos estudos interdisciplinares e a criação de meios de pesquisa para a história ambiental, evidenciando a verdadeira preocupação da instituição em fomentar as pesquisas e estudos nesse campo historiográfico (UNESP, 2015, Online). 
Em relação às outras instituições de ensino superior que possuem a disciplina de história ambiental em seu escopo, tanto na UFRJ quanto na UNB, essas são ministradas na modalidade optativa, sendo que na UNB o curso de história oferece duas disciplinas optativas que se amoldam à visão da história ambiental, sendo elas: "História e Natureza no Brasil", disponível apenas no curso ministrado no período diurno, e "História: natureza e cultura" ofertada no curso de história noturno e diurno. Cumpre ressaltar que na UFRJ a disciplina de História Ambiental intitulada "História e Natureza" é ministrada pelos Drs. Lise Sedrez e José Augusto Pádua, referências em âmbito nacional no estudo da História Ambiental como campo historiográfico.

Somando os cursos de graduação em história ofertados em Goiás (Tabela 1) aos 10 cursos classificados como os melhores do Brasil no ano de 2018 (Tabela 2) totalizamse 25 cursos dos quais apenas 5 (cinco) oferecem a disciplina de história ambiental, o que representa apenas $20 \%$ dos cursos analisados. O índice encontrado é bastante baixo e revela não apenas a insuficiência da oferta da disciplina como, lamentavelmente, o desprestígio dado à matéria nas universidades nacionais.

É importante dizer que o fato de um dentre os principais cursos de história do país ter inserido em sua matriz curricular a disciplina de história ambiental como obrigatória e, ainda, a constatação de que tanto a UNESP em seu campus em Assis quanto a UFRJ terem laboratórios de pesquisa próprios para desenvolver estudos nesta área aponta para o despertar lento, porém perceptível, para relevância da história ambiental como campo historiográfico e a possibilidade de avanço deste campo de estudo nos cursos de história no Brasil. Essa constatação traz uma esperança e deve ser vista de maneira otimista como referência e um passo mais próximo da inserção dos conhecimentos advindos dos estudos envolvendo as questões histórico-ambientais no cenário acadêmico brasileiro.

\section{Conclusão}

Muito embora a história ambiental como campo historiográfico esteja inserida na academia há 46 anos, considerando como marco inicial o curso ministrado por Nash em 1972, no Brasil, conforme demonstrado nesse estudo, a incidência da oferta da disciplina nos cursos de história ainda é muito baixa. Como visto, o cenário dos cursos de graduação em história ofertados pelas universidades goianas não está distante do cotidiano daqueles disponibilizados nas principais universidades brasileiras de modo que a insuficiência 
de oferta da disciplina de história ambiental se apresenta como algo comum à realidade acadêmica nacional.

Há que se destacar que o presente estudo se baseou em uma amostragem temporal e espacial, não abarcando todos os cursos de graduação de história ofertados no Brasil, tampouco em todos os anos de existência dos cursos no país. Todavia, com base na amostragem utilizada, é possível concluir que em âmbito nacional o acesso do acadêmico à disciplina de história ambiental é raro e escasso, não oportunizando a inserção dos acadêmicos às análises interdisciplinares que permeiam o estudo da história pelo aspecto histórico-ambiental.

Uma vez evidenciada a importância da contribuição e da evolução propiciada por meio do estudo da história ambiental, percebe-se que a ausência de oferta de disciplinas voltados para essa área acarreta no engessamento e limitação do modo de se analisar a história, desconsiderando aspectos importantes para a formação do conhecimento ponderados por meio do estudo da história ambiental tais como questões ambientais e sociais que impactam diretamente no curso da história. Assim, observa-se que até o presente momento as universidades brasileiras ainda não atingiram a percepção de quão importante é a história ambiental enquanto campo historiográfico e em termos de aprofundamento no modo de se estudar e vivenciar a história.

\section{Referências}

BUSCA FACULDADE. Estado: Goiás - GO. Disponível em: http://www.buscafaculdade.com/faculdade_estado/ GO/index.html. Acesso em: 07 de junho de 2019.

DUTRA E SILVA, S. et al. O cerrado goiano na literatura de Bernardo Élis sob o olhar da história ambiental. História, Ciências, Saúde - Manguinhos, Rio de Janeiro, v.24, n.1, p.93-110, 2017, Disponível em:<http://www. scielo.br/pdf/hcsm/v24n1/0104-5970-hcsm-S0104-59702016005000024.pdf>.

FACULDADE ALFREDO NASSER. Matriz Curricular. Disponível em: http://www.pucgoias.edu.br/ ArquivisWordpress/cursos/historia/matriz-curricular.pdf. Acesso em: 19 de nov. 2018.

FOLHA DE SÃO PAULO. RUF - Ranking Universitário Folha 2018: história. Disponível em: <https://ruf.folha. uol.com.br/2018/ranking-de-cursos/historia/>. Acesso em: 19 de nov. 2019.

INSTITUTO FEDERAL DE GOIÁS. Licenciatura em História. Disponível em: http://cursos.ifg.edu.br/info/lic/lichistoria/CP-GOIANIA. Acesso em: 19 de nov. 2018.

MINISTÉRIO DO MEIO AMBIENTE. Declaração de Estocolmo sobre o ambiente humano. Disponível em: <www.mma.gov.br/estruturas/agenda21/_arquivos/estocolmo.doc>. Acesso em: 06 de dez. 2018. 
NAÇÕES UNIDAS NO BRASIL. A ONU e o meio ambiente. Disponível em: https://nacoesunidas.org/acao/meioambiente/. Acesso em: 21 de nov. 2018.

ONU - ORGANIZAÇÕES DAS NAÇÕES UNIDAS. Conferência das Nações Unidas sobre o Meio Ambiente Humano. Estocolmo: ONU, 1972.

PÁDUA, J. A. As Bases Teóricas da História Ambiental. Estudos Avançados, São Paulo, v. 24, n. 68, p. 61-101, 2010.

POMBO, O. Interdisciplinaridade e integração dos saberes. Liinc em Revista, v.1, n.1, p. 3- 15, 2005.

PONTIFÍCIA UNIVERSIDADE CATÓLICA DE GOIÁS. Matrizes Curriculares. Disponível em: http://www.pucgoias. edu.br/ArquivisWordpress/cursos/historia/matriz-curricular.pdf. Acesso em: 19 de nov. 2018.

PONTIFÍCIA UNIVERSIDADE CATÓLICA DE SÃO PAULO. História - Matriz Curricular. Disponível em: https:// www.pucsp.br/graduacao/historia\#matriz-curricular. Acesso em: 21 de nov. 2018.

SARTORI, R. C. O pensamento ambiental sistêmico: uma análise científica da ESALQ/USP. 2005. Dissertação (Mestrado em ecologia de agroecossistemas) - Departamento de Ciências Biológicas, Universidade de São Paulo, Piracicaba, 2005.

SOUZA, F. S. de. Rios e terras: história ambiental de Goiás (1822-1850). 2013. Dissertação (Mestrado em História). Departamento de História. Universidade Estadual Paulista Júlio de Mesquita Filho (Campus de Assis).

SOUZA, F. S. de. Temas e Métodos para uma História Ambiental do Brasil Império. XXVI Simpósio Nacional de História - ANPUH, Anais..., São Paulo, p. 1-11, 2011.

UNIVERSIDADE DE SÃO PAULO. Faculdade de Filosofia letras e Ciências Humanas - USP. História. Disponível em: http://graduacao.fflch.usp.br/sites/graduacao.fflch.usp.br/files/GRADE\%20CURRICULARbacharelado.pdf. Acesso em: 21 de nov. 2018.

UNIVERSIDADE DE BRASÍLIA. Currículo da Habilitação - História. Disponível em: https://matriculaweb.unb. br/graduacao/curriculo.aspx?cod=3425. Acesso em: 21 de nov. 2018.

UNIVERSIDADE ESTADUAL DE CAMPINAS. Instituto de Filosofia e Ciências Humanas. Disciplinas. Disponível em: https://www.ifch.unicamp.br/ifch/timegrid/graduacao/disciplinas. Acesso em: 21 de nov. 2018.

UNIVERSIDADE ESTADUAL DE GOIÁS. Núcleo Livre. Disponível em: http://www.prg.ueg.br/conteudo/8538_ nucleo_livre. Acesso em: 19 de nov. 2018.

UNIVERSIDADE ESTADUAL DE GOIÁS. História. Disponível em: http://www.ueg.br/exec/consulta_ cursos/?funcao=dados_v2\&variavel=16\&mod=2. Acesso em: 19 de nov. 2018.

UNIVERSIDAde eSTADUAL PAULISTA "JÚLIO DE MESQUITA". Projeto Pedagógico. Câmpus Assis, 2015. Disponível em: http://www.assis.unesp.br/\#!/graduacao/secao-de-graduacao/cursos/historia/projetopedagogico/. Acesso em: 21 de nov. 2018.

UNIVERSIDADE ESTADUAL PAULISTA “JÚLIO DE MESQUITA". Faculdade de Ciências Humanas e Sociais - Câmpus de Franca. Grades Curriculares - História. Disponível em: https://www.franca.unesp.br/\#!/graduacao/cursosde-graduacao/. Acesso em: 21 de nov. 2018.

UNIVERSIDADE FEDERAL DA BAHIA. Faculdade de Filosofia e Ciências Humanas. História. Disponível em: https://ffch.ufba.br/?q=historia-0. Acesso em: 21 de nov. 2018.

UNIVERSIDADE FEDERAL DE GOIÁS. Matriz Curricular do Curso de Graduação em História - Licenciatura. Disponível em: https://www.historia.ufg.br/p/24170-estrutura-curricular. Acesso em: 19 de nov. 2018. 
UNIVERSIDADE FEDERAL DE GOIÁS. Matriz Curricular do Curso de História. Disponível em: https://www. historia.ufg.br/p/24211-estrutura-curricular. Acesso em: 19 de nov. 2018.

UNIVERSIDADE FEDERAL DE MINAS GERAIS. Departamento de História - Faculdade e Filosofia e Ciências Humanas. Disponível em: http://www.fafich.ufmg.br/atendimento/historia/Projeto\%20Pedagogico\%20 do\%20Curso\%20de\%20Historia.pdf/view. Acesso em: 21 de nov. 2018.

UNIVERSIDADE FEDERAL DO RIO DE JANEIRO. Instituto de História. Confira a grade horária 2018.1. Disponível em: http://cpro16197.publiccloud.com.br/tempsite/IH/images/documentos/GRADE_HORARIA_20181_1.pdf. Acesso em: 21 de nov. 2018.

UNIVERSIDADE FEDERAL DO RIO GRANDE DO SUL. História. Disponível em: http://www.ufrgs.br/ufrgs/ensino/ graduacao/cursos/exibeCurso?cod_curso=333. Acesso em: 21 de nov. 2018.

UNIVERSIDADE FEDERAL FLUMINENSE. História - graduação em História. Estrutura Curricular. Disponível em: http://www.historia.uff.br/grad/estrutura_curr.php. Acesso em: 21 de nov. 2018.

WORSTER, D. Para Fazer História Ambiental. Estudos Históricos. Rio de Janeiro: FGV, vol. 4, n.8, p. 198-215, 1991. 